\title{
Changes in Aerobic Ability During A Macro Cycle of Training in Swimming
}

\author{
Daniel A. Marinho ${ }^{1,2}$, Nuno Garrido ${ }^{2,3}$, Victor M. Reis ${ }^{2,3}$, António J. Silva ${ }^{2,3}$, Aldo M. Costa ${ }^{1,2}$, \\ David Sousa $^{1,2}$ and Mário C. Marques ${ }^{1,2, *}$ \\ ${ }^{I}$ University of Beira Interior, Sport Sciences Department (UBI, Covilhã, Portugal) \\ ${ }^{2}$ Research Centre in Sports, Health and Human Development (CIDESD, Vila Real, Portugal) \\ ${ }^{3}$ University of Trás-os-Montes and Alto Douro. Department of Sport, Health and Exercise (UTAD, Vila Real, \\ Portugal)
}

\begin{abstract}
It seems that critical velocity and critical stroke rate are associated with aerobic performance. The aim of this study was to analyse the changes of critical velocity and critical stroke rate during 12 weeks of training in a group of young competitive swimmers. Fourteen age group male swimmers took part in this investigation. The evaluation took place in two different trials. The first one was conducted at the beginning of the season and the second one after 12 weeks of training. For each subject the critical velocity and the critical stroke rate were determined in both trials. The main result was that critical velocity increased, whereas critical stroke rate decreased between the first and second trials. It seems that technical ability was improved during the 12 weeks of training. The swimmers were able to perform at the same physiological intensity at higher velocities and with less stroke rate.
\end{abstract}

Keywords: Age group swimmers, aerobic capacity, technique, training effects.

\section{INTRODUCTION}

Critical velocity was defined as the maximum swim speed that can be maintained during a long period of time without exhaustion [1]. Besides the concept of critical velocity which is frequently used by coaches as a method to determine the intensity of swimmers' aerobic capacity, Pelayo et al. [2] were pioneers in hypothesising the existence of a theoretical stroke rate that could be maintained without exhaustion during a long period of time, defined as critical stroke rate. It seems that critical velocity and critical stroke rate are associated with aerobic performance. However, these two variables are not always linked together during training. On this, it is unclear whether an improvement of the aerobic capacity (e.g. critical velocity) is dependent on bioenergetical and/or biomechanical enhancement (technical efficiency). Therefore, the aim of this study was to analyse the changes of critical velocity and critical stroke rate during 12 weeks of training in a group of young competitive swimmers.

\section{METHODS}

Fourteen age group male swimmers took part in this investigation. The mean age, height, body mass and years of

*Address correspondence to this author at the Department of Sport Sciences, University of Beira Interior - Portugal, Rua Marquês D’Ávila e Bolama, 6200-001 Covilhã, Portugal; Tel: +(351) 275329153; Fax: +(351) 275329157; E-mail: mariomarques@mariomarques.com competitive practice were: $13.60 \pm 0.21$ years old, $1.60 \pm 0.10$ $\mathrm{m}, 49.07 \pm 13.69 \mathrm{~kg}$, and $4.43 \pm 0.51$ years. The evaluation took place in two different trials. The first one was conducted at the beginning of the season and the second one after 12 weeks of training. For each subject the critical velocity and the critical stroke rate were determined in both trials.

\section{RESULTS}

The main result was that critical velocity increased (from $1.07 \pm 0.09$ to $1.10 \pm 0.10 \mathrm{~m} / \mathrm{s}, \mathrm{p}<0.05$ ), whereas critical stroke rate decreased between the first and second trials (from $1.10 \pm 0.09$ to $1.05 \pm 0.08$ cycles/s, $\mathrm{p}<0.05$ ).

\section{DISCUSSION}

It seems that technical ability was improved during the 12 weeks of training. The swimmers were able to perform at the same physiological intensity at higher velocities and with less stroke rate. This information could help swimming coaches monitoring their training without expensive instruments, as suggested by Renoux [3].

\section{REFERENCES}

[1] Wakayoshi K, Ikuta K, Yoshida T, et al. Determination and validity of critical velocity as an index of swimming performance in the competitive swimmer. Eur J Appl Physiol Occup Physiol 1992; 64: 153-7.

[2] Pelayo P, Dekerle J, Delaporte B, Gosse N, Sidney M. Critical speed and critical stroke rate could be useful physiological and 
technical criteria for coaches to monitor endurance performance in competitive swimmers. In: Sanders R, Hong Y, Eds. Proceedings of XVIII International Symposium on Biomechanics in Sport; 2000: Hong Kong: The Chinese University of Hong Kong: 2005; pp. 83-7.
[3] Renoux JC. Evaluating the time limit at maximum aerobic speed in elite swimmers: training implications. Arch Physiol Biochem 2001; 109: 424-9.

Received: July 05, 2009

Revised: October 18, 2009

Accepted: November 09, 2009

(C) Marinho et al.; Licensee Bentham Open

This is an open access article licensed under the terms of the Creative Commons Attribution Non-Commercial License

(http://creativecommons.org/licenses/by-nc/3.0/) which permits unrestricted, non-commercial use, distribution and reproduction in any medium, provided the work is properly cited. 